\title{
Detetive da saúde: a contribuição de um jogo de tabuleiro para o ensino e a aprendizagem na área da saúde
}

José Fabiano Costa Justus

Antonio Carlos de Francisco

\section{Resumo}

O presente artigo tem por objetivo identificar as contribuições de um método de ensino, centrado numa abordagem lúdica de educação, para o ensino e a aprendizagem de discentes de um curso profissionalizante da área da saúde. A pesquisa se caracteriza como aplicada, exploratória, interpretativa, predominantemente qualitativa e com resquícios de pesquisa bibliográfica. 0 público alvo foi de alunos da terceira série do curso Técnico em Farmácia de uma instituição particular de ensino em Ponta Grossa, no Paraná. A pesquisa utilizou um método ancorado em dois meios de ensino: a aula com exposição pelo professor e o desenvolvimento de um jogo de tabuleiro intitulado Detetive da Saúde. Os dados, obtidos através de entrevistas, evidenciaram as percepções dos sujeitos da pesquisa quanto ao meio de ensino utilizado. As principais percepções assinalam que o jogo desenvolvido facilita a aprendizagem, possibilita maior envolvimento, permite distração, necessita de conhecimentos prévios e possibilita revisão de conteúdos.

Palavras-chave: Ensino-aprendizagem em saúde, jogo educativo, meios de ensino, ensino técnico e profissionalizante.

\section{Abstract}

Detective health: the contribution of a board game for teaching and

\section{learning in health}

This study aims to identify the contributions of a teaching method, centered in a ludic education approach, for the teaching and learning of students of a professional course in the health area. This research is applied, exploratory, interpretative, mostly qualitative and with bibliographic research parts. The target public was from the third grade from the Technical Pharmacy Course from a private

R. B. E. C. T., vol 5, núm 1, jan./abr. 2012 ISSN - 1982-873X 
teaching institution in Ponta Grossa, Paraná. The research used a methodology based on fronts: a class with the exposition made by the teacher and a development of a board game named Health Detective. The data was collected through a questionnaire with open questions and non-structured interviews. The data, obtained through the interviews, highlighted the perception of the students involved in the research considering the teaching methodology used. The main perceptions showed that the developed game makes the learning process easier, allows a higher involvement, allows distraction, demands previous knowledge and allows subjects reviews.

Keywords: Education-learning in health, educational game, teaching ways, technical and professional education.

\section{Introdução}

A busca por situações, produtos, materiais, procedimentos capazes de gerar saúde advém dos mais primitivos hominídeos, conservando-se intensa nos dias atuais. Assim, os profissionais da área da saúde devem deter formação geral e competências capazes de atender às necessidades básicas de saúde da população. O perfil profissional do aluno concluinte do Curso Técnico em Farmácia de uma instituição particular de ensino, em Ponta Grossa, previsto no documento de Reconhecimento e Renovação desse curso, objetiva atender tais necessidades. Para tanto, espera-se do profissional egresso deste curso uma capacidade desenvolvida de fornecer orientações aos pacientes/clientes; bem como promover ações de saúde na comunidade.

Neste contexto, o docente do Ensino Profissionalizante necessita fazer uso de práticas pedagógicas capazes de desenvolver no aluno essa habilidade específica. Exigindo, muito além do que a simples transmissão de conhecimentos técnicos, a formação de indivíduos capazes de transitar entre as teorias apresentadas e a prática profissional.

Porém, a complexidade dos temas abordados no Ensino Profissionalizante da área da saúde muitas vezes leva o aluno a deter-se no domínio das técnicas necessárias à execução do trabalho, em detrimento de uma interação consciente da utilização desses conhecimentos com as necessidades da comunidade.

Essa segmentação entre o conhecimento científico e sua aplicação em benefício da comunidade que se percebe no ensino da saúde ainda é resquício do Relatório Flexner (1910). Esse relatório é um documento que orientou mudanças nas escolas de Medicina e, por 
conseguinte, nas escolas de saúde como um todo, mas que descuidava da abordagem holística da saúde do ser humano.

Os tempos atuais, por sua vez, determinam transformações nesse modelo. Maiores exigências quanto aos cuidados com a saúde, necessidades de humanização dos serviços de saúde, e pensar o cidadão e a sociedade durante o exercício profissional, requerem indivíduos que possam transladar entre conhecimentos técnicos e sua aplicação em benefício da sociedade.

Cirino e Toralles-Pereira (2004) apontam para a dificuldade de formar profissionais de saúde com competências que Ihes possibilitem recobrar a dimensão essencial do cuidado: a relação entre humanos.

Desse modo, ferramentas que facilitem o translado entre teorias e prática profissional voltada à saúde coletiva despontam como meios de ensino utilizados por cursos da área da saúde a fim de impregnar de cotidiano as teorias e técnicas características da área.

A disciplina Dispensação de Produtos Farmacêuticos e Correlatos do Curso Técnico em Farmácia de uma instituição particular de ensino, em Ponta Grossa, no Paraná, objetiva apresentar ao aluno conceitos e definições acerca dos mecanismos gerais de ação de produtos terapêuticos. Também aborda os cuidados a serem considerados e orientações que devem ser prestadas ao cliente no momento da dispensação (entrega do produto terapêutico). Tal disciplina assume, assim, uma atenção maior com a saúde do cliente/paciente.

Porém, corroborando Cirino e Toralles-Pereira (2004), observa-se dificuldade dos discentes do Curso Técnico em Farmácia dessa instituição em relacionar o cotidiano da prática profissional com conceitos apresentados durante as aulas da disciplina de Dispensação de Produtos Farmacêuticos e Correlatos. Demonstrando, dessa forma, que o método empregado nessa modalidade de ensino não se faz suficientemente eficaz para a obtenção de um dos objetivos da referida disciplina.

Este estudo, então, visa implementar um método de ensino centrado numa abordagem lúdica (capaz de despertar prazer) de educação e focado nas tendências atuais de escolas da área da saúde. Tal método objetiva a redução de lacunas existentes no processo de ensino e aprendizagem pela dificuldade de transição entre teorias acadêmicas e práticas profissionais.

Assim, a pergunta de partida para esta pesquisa foi: quais as contribuições de um método de ensino, centrado numa abordagem lúdica de educação, para o ensino e a aprendizagem de discentes de um curso profissionalizante da área da saúde? 


\section{Tendências atuais e alternativas educativas utilizadas nos cursos da área da saúde}

Presentemente há um movimento de mudança de paradigmas no que tange as tendências curriculares voltadas para a área da saúde. O paradigma flexneriano (pós Relatório Flexner), bastante presente nos dias atuais, que prevê a fragmentação do conhecimento em especialidades, descuida da abordagem holística da saúde do ser humano (inteiro e único no seu contexto). Todavia a conjuntura atual se faz favorável a tal mudança paradigmática em virtude das "reivindicações por serviços de saúde mais humanizados, grande necessidade de atenção à saúde da população brasileira; altos custos dos serviços de saúde em especialidades e inadequação da formação dos profissionais da saúde" (Lampert, 2002, p.2).

Essa nova tendência denominada paradigma da integralidade "(ibid, 2002, p.102) passa a considerar o objeto da atenção (o paciente, o usuário, o cidadão, a coletividade) como ator no processo de saúde. Impele um movimento de reconstrução que se realiza tanto no plano dos cuidados de saúde quanto na formação dos profissionais dessa área.

Assis (2001, p. 139), versando sobre essa necessidade de reestruturação para a formação dos profissionais da saúde assevera que "a complexidade da saúde exige realmente inovações que superem a assepsia técnica e propiciem a interação com a dinâmica popular".

Assim, as instituições de ensino devem orientar-se por um compromisso efetivo com a sociedade, "o que significa concretamente a integração com os serviços de saúde em função dos reais interesses de saúde da população" (Lampert, 2002, p.104).

\section{A corrente ausubeliana da aprendizagem significativa}

A teoria ausubeliana da aprendizagem significativa tem como foco a proposta de David Ausubel (1970). Conforme Moreira (2008), a aprendizagem significativa é a aprendizagem com compreensão, com significado, com possibilidade de transferência, com capacidade explicativa, com maior retenção.

Segundo a teoria ausubeliana ocorre no cérebro um armazenamento de informações de forma hierárquica, de tal maneira que elementos menos importantes são ligados a conceitos maiores, mais inclusivos e mais gerais. Desse modo, a estrutura cognitiva representa um arcabouço de conceitos hierarquicamente organizados (denominados subsunçores), que são as representações da experiência sensorial do indivíduo. 
Para Moreira (2008, p.19), subsunçor é um conhecimento prévio (conceito, idéia, proposição, representação) que servirá de ancoradouro para o novo conhecimento e, ao mesmo tempo, se modificará em função da ancoragem.

O aluno constrói significados no momento em que estabelece interações não-literais (ou substantiva) e não-arbitrárias entre o que conhece de aprendizagens anteriores e o que aprende de novo. Diz-se que não são arbitrárias porque o novo conhecimento não interage com um conhecimento qualquer, mas sim com um conhecimento específico. E substantivas (ou nãoliterais) porque o novo conhecimento deve ser internalizado ou reconstruído internamente baseado em significados pessoais (chamados conotativos) e significados compartilhados por uma comunidade (chamados de denotativos).

Assim, para que se dê a aprendizagem significativa uma das condições é que o aprendiz detenha "em sua estrutura cognitiva conhecimentos prévios adequados para dar significado aos novos conhecimentos. A outra é que ele ou ela queira dar significado a esses novos conhecimentos" (Moreira, 2008, p.16).

Quando o conteúdo a ser internalizado não consegue ligar-se a algo já conhecido, a teoria ausubeliana propõe a ocorrência de aprendizagem mecânica ou automática. Nesse tipo de aprendizagem diz-se que o novo conceito é armazenado arbitrariamente (sem dar significado) e não se relaciona a subsunçores específicos. Ausubel não estabelece que a aprendizagem mecânica e a aprendizagem significativa sejam uma dicotomia, "mas sim como duas extremidades de um contínuo" (Moreira, 2008, p.10), podendo ocorrer uma, outra, ou ambas.

\section{Métodos e Meios de Ensino}

O processo de ensino é marcado pela simbiose das atividades do discente e do docente. A direção do estudo é dada pelo docente que deve planejar aulas, conteúdos, métodos, enfim, formas de o discente desenvolver suas capacidades mentais.

O processo de ensino deve focar a aprendizagem. Turra et al (1995) asseveram que "um modelo de ensino centrado nos objetivos representa uma valiosa ajuda ao professor na seleção dos procedimentos necessários ao tipo de aprendizagem em questão". (Turra et al, 1995, p. 125)

Quando um professor, "ao dirigir e estimular o processo de ensino em função da aprendizagem dos alunos, utiliza um conjunto de ações, passos, condições externas e procedimentos" executa, conforme Libâneo (1994, p.150), um método de ensino.

O método de ensino, além dos objetivos, deve tomar como base um conteúdo (objeto, fenômeno, problema, matéria). Também deve ser levado em consideração que os fatos, fenômenos, processos estão em constante desenvolvimento em virtude da ação humana. Nesse contexto, o método de ensino implica analisar o objeto de estudo sob vários aspectos: suas 
propriedades, suas relações com outros fenômenos e suas implicações com a prática social, "uma vez que a apropriação de conhecimentos tem a sua razão de ser na sua ligação com as necessidades da vida humana e com a transformação da realidade social”' (Libâneo, 1994, p. 151).

Os métodos de ensino são diversos. Cada qual com suas características. A seleção de métodos, por si só já é uma tarefa árdua. E torna-se mais complexa quando se percebe que, numa mesma turma, existem diferenças entre os estudantes. Assim um único método pode não ter o mesmo valor para todos os estudantes.

Dentre os métodos de ensino, destaca-se para este trabalho o método da exposição pelo professor e o método de trabalho em grupo. O método da exposição pelo professor consiste na explicação ou demonstração dos conhecimentos e tarefas pelo docente, cabendo aos alunos uma ação receptiva, porém não necessariamente passiva. Essa passividade do discente é uma das limitações que devem ser superadas. Nessa intenção, Libâneo (1994, p. 161) assegura que, quando o professor consegue mobilizar a atividade interna do aluno de concentrar-se e de pensar, a exposição lógica da matéria é um importante procedimento para se obter conhecimento.

Independente de quais foram elencados, Libâneo (1994, p. 149) assevera sobre os métodos de ensino, que "estão orientados para objetivos; implicam uma sucessão planejada e sistematizada de ações, tanto do professor quanto dos alunos; requerem a utilização de meios" (grifo do autor).

Para este estudo, empregaremos a acepção de Libâneo (idem, p. 149) para meio de ensino como sendo o(s) recurso(s) material(is) utilizado(s) pelo docente para a concretização dos métodos de ensino.

\section{Jogos como meio de ensino}

A utilização de jogos no ensino é apresentada como uma estratégia viável para contribuir com o processo de ensino e aprendizagem. É assinalada por Neves e Pereira (2006, p. 100) como uma forma de os professores aperfeiçoarem suas práticas pedagógicas renovando ações na busca de "aumentar a motivação para a aprendizagem, a autoconfiança, a organização, a concentração, a atenção, o raciocínio lógico-dedutivo e o senso cooperativo" de seus alunos. Dohme (2006, p.20) apóia a utilização de jogos na educação quando assegura que

"Os jogos são importantes instrumentos de desenvolvimento de crianças $e$ jovens. Longe de servirem apenas como fonte de diversão, o que já seria importante, eles propiciam situações que podem ser exploradas de diversas maneiras educativas." 
Neves e Pereira (2006, p.99) apontam para alguns benefícios da utilização de jogos como ferramenta metodológica de apoio ao ensino e aprendizagem:

"- conseguimos detectar os alunos que estão com dificuldades reais;

- os alunos demonstram para seus colegas e professores se o assunto foi bem assimilado;

- existe uma competição entre os jogadores e os adversários, pois almejam vencer e, por isso, aperfeiçoam-se e ultrapassam seus limites;

- não existe o medo de errar, pois o erro é considerado um degrau necessário para se chegar a uma resposta correta;

- o aluno se empolga com o clima de uma aula diferente, o que faz com que aprenda sem perceber."

A capacidade que o jogo apresenta de permitir que o erro seja um degrau necessário à resposta correta (Neves; Pereira, 2006) deve ser considerada indispensável ao ensino profissionalizante e é confirmada por Kishimoto (1998, p.40), quando este assinala que "a conduta lúdica oferece oportunidades para experimentar comportamentos que, em situações normais, jamais seriam tentados pelo medo do erro ou punição". Essa capacidade deve ser explorada pelos cursos de formação de profissionais da área da saúde, pois permite ao discente um treinamento isento da possibilidade de causar ônus aos usuários dos serviços de saúde.

\section{Aprendizagem através de jogos e técnicas vivenciais:}

Abordando o desenvolvimento geral, Gramigna (2007, p.1) o caracteriza como "qualquer mudança para melhor, por menor que seja, detonada por uma força interna ou externa à pessoa". Porém deixa claro que essa mudança se inicia na própria pessoa, corroborando com a teoria ausubeliana que prevê a intencionalidade para a aprendizagem significativa.

Cinco estágios devem ser percorridos para que tal mudança/desenvolvimento se concretize.

O primeiro estágio, ligado ao nível de informação que cada ator tem acesso e à forma de percebê-los, compara-se aos subsunçores antevistos na Aprendizagem Significativa.

O segundo estágio, ligado diretamente aos valores pessoais, segue pelo campo das emoções e sentimentos. Está relacionado ao "querer" e, portanto, depende do sujeito assemelhando-se à intencionalidade ausubeliana. Um facilitador (cabe aqui destacar que o termo é facilitador, diferenciando claramente de um mero condutor do processo) pode sim estimular o "querer", mas não o impor. E o facilitador pode percebê-lo em manifestações individuais de aprovação ou não. 
O terceiro estágio é o esforço individual através do qual se procura implantar mudanças, desenvolver habilidades. É nessa fase que se seleciona o que pode ser útil (significativo) e o que será descartado. Para essa fase podemos encontrar apoio em Ausubel na dissociação que precede a assimilação obliteradora.

O quarto estágio desprende-se da teoria ausubeliana por envolver a ação individual. Fechando o ciclo da mudança individual o sujeito, depois de analisar as três etapas anteriores, age de forma modificada. Essa transformação da ação é uma possibilidade para contemplar as mudanças de paradigmas previstas para as escolas de saúde, outrora discutidas nessa dissertação.

O quinto estágio previsto por Gramigna (2007) completa o processo de desenvolvimento e se concretiza quando o sujeito, agora transformado, arrebanha adeptos às suas práticas, conseguindo o engajamento de outros atores em prol da transformação.

Gramigna (2007) assevera como forças restritivas para o processo de desenvolvimento as crenças e valores individuais; dificuldades pessoais; pressão de grupos. Aponta, também, forças propulsoras desse processo como a eterna insatisfação do ser humano, buscando significados novos para a vida; e o grande potencial do ser humano que, às vezes, necessita de estímulos para ser revelado.

Diversas práticas podem ser utilizadas nesse intuito. O jogo é apresentado por Gramigna (2007) como um aplicativo na linha participativo-vivencial capaz de facilitar o desenvolvimento. Também assinala que a grande adesão aos jogos se deve às vantagens e resultados que podem ser obtidos com sua utilização.

A aprendizagem vivencial é conseqüência do envolvimento dos indivíduos em atividades que, além de vivenciadas, permitam analisar o processo, extrair algum insight útil e aplicar o aprendizado em seu cotidiano.

O Ciclo da Aprendizagem Vivencial (CAV), proposto por Gramigna (2007), se completa ao serem concluídas cinco etapas: vivência, relato, processamento, generalização, aplicação.

A primeira etapa do CAV, a vivência, refere-se ao jogo em si. Para facilitar o envolvimento do grupo e estimular a motivação. É importante que essa atividade seja "atrativa, lúdica, surpreendente e fascinante" (Gramigna, 2007, p.14).

Após a vivência, o relato permite ao facilitador abrir espaço para demonstrações de sentimentos. Para isso pode-se fazer uso de registros por escrito, discussão livre, entre outras estratégias.

O processamento, a terceira fase do CAV, visa avaliar o processo em grupo elencando, por exemplo, facilidades e dificuldades para cumprir o objetivo do jogo e questionamento individuais. 
A quarta etapa do CAV, a generalização, objetiva comparar o jogo com a realidade laboral. É considerado o melhor momento para a introdução de temas, informações técnicas e referenciais teóricos no caso de treinamentos e desenvolvimentos.

O ciclo da aprendizagem vivencial é finalizado com a aplicação. Nesse momento, cada jogador estabelece uma parcela de responsabilidade futura na busca de melhorias. 0 comprometimento com as mudanças é o principal objetivo a ser buscado nesta fase.

Ao optar por esse método, o facilitador deve utilizar um jogo ou vivência que possibilite percorrer todo o CAV.

\section{Metodologia}

Este trabalho se caracteriza como uma pesquisa aplicada, exploratória, interpretativa, predominantemente qualitativa e com resquícios de pesquisa bibliográfica. E os instrumentos de coleta de dados empregados foram questionários, entrevistas não-estruturadas e observação sistemática.

É uma pesquisa aplicada, pois objetiva a utilização de conhecimentos adquiridos para a aplicação prática. Envolve interesses e verdades locais e está dirigida para a solução de problemas específicos (SILVA e MENEZES, 2001, p. 20).

Também se apresenta como uma pesquisa exploratória uma vez que, a partir do método de ensino utilizado, será permitindo ao pesquisador conhecer sobre o assunto pesquisado, a fim de desenvolver conceitos e hipóteses posteriores.

Caracteriza-se como pesquisa interpretativa devido enfocar o comportamento social no cenário natural (a sala de aula); suas observações e interpretações serem feitas no contexto da totalidade das interações humanas (visão holística do processo); e a análise dos dados envolverem a contextualização, onde os resultados da pesquisa são interpretados com referência no grupo, cenário ou evento em particular que estiver sendo observado (MOREIRA e CALEFFE, 2008, p.86).

Segundo Moreira e Caleffe (2008, p. 67) "os pesquisadores interpretativos estão preocupados em qualificar através dos olhos dos participantes ao invés de quantificar através dos olhos do observador". Assim sendo, a tônica da pesquisa é qualitativa. Essa caracterização se oferece uma vez que o estudo esbarra em limitações de população (a amostra é composta por apenas nove sujeitos); a existência de parâmetros não mensuráveis (como o tempo real de estudo de cada indivíduo, por exemplo), bem como a construção das percepções dos discentes quanto à atividade desenvolvida se dar de forma subjetiva. Silva e Menezes (2001, p. 20) afirmam que "a interpretação dos fenômenos e a atribuição de significados são básicas no processo da pesquisa qualitativa".

R. B. E. C. T., vol 5, núm 1, jan./abr. 2012 ISSN - 1982-873X 
Assim, tônica qualitativa desta pesquisa será baseada na análise do discurso das entrevistas aplicadas, objetivando averiguar as percepções dos alunos acerca da metodologia utilizada e suas implicações. Segundo Macedo, et al (2008, p. 650) ao realizar a análise em si, se consegue construir uma interpretação que permite captar o sentido não aparente do discurso. Porém, nuances quantitativas estão presentes na pesquisa ao coletar parte dos dados através de questionários facilmente mensuráveis. Moreira e Caleffe (2008, p. 67) abalizam essa simbiose qualitativa-quantitativa argumentando que "dados quantitativos necessitam ser suplementados por detalhes contextuais fornecidos pelas técnicas qualitativas". São evocados, ainda, resquícios de pesquisa bibliográfica, pois também leva em consideração materiais já publicados para fundamentar a temática estudada.

A pesquisa foi desenvolvida no Colégio Sant Ana, uma instituição particular de ensino, em Ponta Grossa, no Paraná, e tem como universo a turma de terceira série, do curso Técnico em questão, modalidade Concomitante ao Ensino Médio. Tal turma de terceira série é composta por 9 (nove) sujeitos regularmente matriculados na instituição, sendo formada por 2 (dois) alunos e 7 (sete) alunas, com idades entre 16 e 17 anos.

O estudo se deu nas aulas da disciplina Dispensação de Produtos Farmacêuticos e Correlatos. Essa disciplina prevê, para o concluinte do curso, a capacidade de "aplicação de técnicas de atendimento e orientação ao cliente, fornecendo informações quanto ao uso correto e efeitos colaterais dos produtos dispensados, respeitando os limites de atuação" (Colégio Sant'Ana, 2008). As Bases Teóricas sugeridas para o desenvolvimento dessa disciplina englobam estudos de grupos farmacológicos (medicamentos que agem sobre os diversos sistemas do organismo), e outros como antibióticos, antifúngicos, antivirais, medicamentos que interferem no metabolismo e nutrição.

\section{A Pesquisa}

O início da investigação se deu com o desenvolvimento de um dos temas previstos no ementário da disciplina sendo ministrado através da exposição do assunto pelo "professor / pesquisador" (Moreira; Caleffe, 2008, p. 39) aos alunos da terceira série do curso Técnico em Farmácia.

O assunto elencado para o estudo foi Fármacos Relacionados ao Metabolismo dos Carboidratos, sendo parte integrante da Base Teórica sugerida pelo documento de Renovação do Curso Técnico em Farmácia: “... medicamentos que agem sobre os diversos sistemas do organismo...". Tal tema refere-se ao grupo de drogas que atuam no combate ao diabetes 
relacionando, assim, os conceitos teóricos com o cotidiano. A escolha deste tema fundamentouse em Goodman \& Gilmam que asseveram que

"Nesses últimos anos, os países desenvolvidos testemunharam um aumento explosivo na prevalência do diabetes melito (DM) predominantemente relacionado com mudanças no estilo de vida e consequente surto da obesidade. As consequências metabólicas da hiperglicemia e dislipidemia prolongadas, $[\ldots]$, representam enorme carga para os pacientes com diabetes melito e $o$ sistema de saúde pública. A maior compreensão da patogenia do diabetes $e$ suas complicações, bem como os avanços na sua terapia e prevenção são de suma importância para fazer frente a esse desafio de saúde." (Goodman \& Gilman, 2006, p. 1459).

A exposição verbal do tema foi o principal método empregado na etapa inicial do estudo, porém a ilustração com imagens referentes ao tema, demonstração através de esquemas relacionados ao assunto e a exemplificação com casos clínicos foram métodos complementares e enriquecedores utilizados.

Depois de concluída a exposição do assunto Fármacos Relacionados ao Metabolismo dos Carboidratos, foi agendada para a aula seguinte a aplicação de um questionário formulado com questões abertas, que permitiu verificar o aproveitamento dos alunos acerca do tema apresentado.

O questionário foi analisado pelo pesquisador e a análise não foi apresentada aos alunos. 0 docente procedeu a um levantamento a fim de verificar as questões com menor percentual de respostas satisfatórias. Tal levantamento embasou a formulação de dicas que foram fornecidas aos discentes durante a aplicação do jogo Detetive da Saúde, conforme será elucidado na sequência.

Os participantes da pesquisa foram informados que o desígnio do jogo é servir como uma estratégia diferenciada para a aprendizagem. Os discentes também foram avisados sobre a aplicação de um novo questionário após a execução do jogo.

$\mathrm{Na}$ aula subsequente à primeira aplicação do questionário, foi desenvolvido o jogo de tabuleiro Detetive da Saúde. Tal jogo teve duração de uma hora-aula e sua dinâmica se baseou no fornecimento de dicas acerca do assunto Fármacos Relacionados ao Metabolismo dos Carboidratos, que foram providas à medida que os participantes, após jogar um dado, moveram fichas sobre um tabuleiro em formato de corpo humano estilizado e dividido em casas.

O tabuleiro do jogo foi confeccionado em EVA (Etileno Acetato de Vinila) de diversas cores, criando um modelo representativo para cada um dos principais órgãos que compõem o corpo humano. Os modelos representativos de cada porção do corpo humano foram fixados com cola e dispostos de acordo com a figura a seguir. As casas pelas quais os grupos percorreram o tabuleiro 
durante o jogo Detetive da Saúde foram confeccionadas também em EVA, e organizadas de modo a criar uma sequência numérica que facilitou o desenvolvimento da atividade. $O$ tabuleiro finalizado para o jogo Detetive da Saúde está demonstrado na figura que segue.

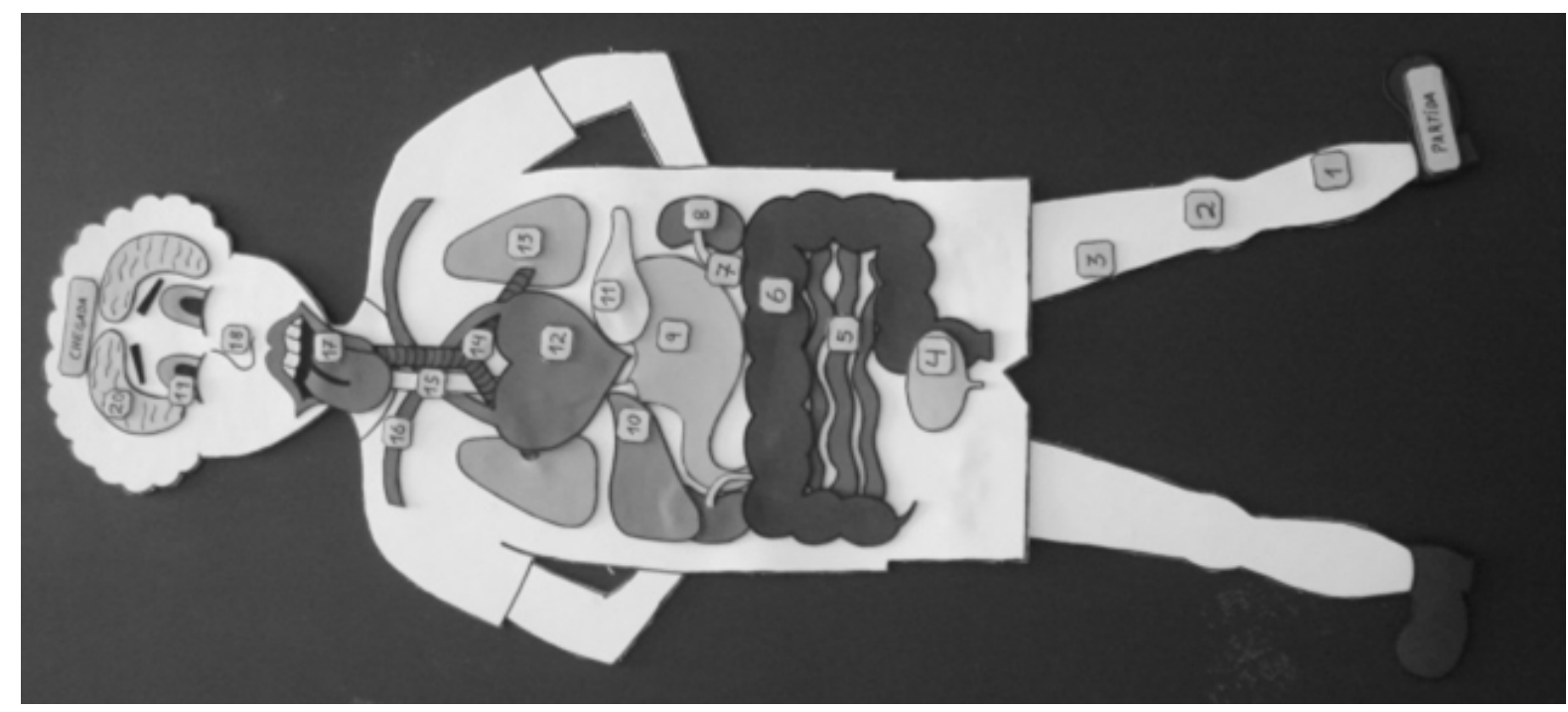

Figura 1: Tabuleiro utilizado para o desenvolvimento do jogo Detetive da Saúde

Fonte: o autor

Durante a aula prevista para a aplicação da atividade lúdica intitulada Detetive da Saúde, o pesquisador conduziu o jogo, inicialmente lendo as seguintes orientações:

Para jogar o Detetive da Saúde, os participantes devem seguir algumas regras:

O objetivo do Detetive da Saúde é descobrir quem é o vilão que afeta a saúde do paciente.

Primeiramente, os participantes do jogo devem estar distribuídos em 5 grupos. Cada grupo receberá uma ficha com a cor que caracteriza seu grupo (azul, amarelo, verde, vermelho, laranja);

Todos os grupos devem iniciar o jogo na casa PARTIDA;

A ordem em que os grupos participarão do jogo será determinada jogando o dado e dispondo os grupos do maior para o menor número obtido;

* Caso mais de uma equipe obtenha o mesmo valor no dado, deverão jogar o dado novamente até que se determine uma ordem para todos os grupos.

Cada grupo, em sua vez, deverá jogar o dado, andar com sua ficha o número de casas indicado e ouvir uma DICA que ajudará a descobrir o vilão desse jogo;

Todos os jogadores, mesmo dos outros grupos, devem prestar atenção às DICAS, pois, a partir delas, é que os participantes descobrirão quem é o vilão; 
Para vencer o jogo, o grupo deverá alcançar casa CHEGADA e responder à pergunta final de forma acertada. Caso erre a resposta, deverá retornar e permanecer na casa em que se encontrava anteriormente até chegar novamente sua vez de jogar.

\section{A pergunta final é: QUEM É O VILÃO DESSE CASO?}

*IMPORTANTE: Caso seu grupo descubra quem é o vilão antes de alcançar a casa CHEGADA, não deve contar a ninguém, para poder ganhar o jogo e ter direito a um prêmio.

O primeiro grupo a alcançar a casa CHEGADA e responder corretamente à PERGUNTA FINAL será o vencedor e terá direito a um "kit alimentação saudável", composto pelas frutas pera, maçã, morango, uva e laranja.

À medida que os outros grupos alcancem a casa "CHEGADA" terão direito a escolher entre outros "kits alimentação saudável", compostos por peras ou maçãs ou morangos ou uvas ou laranjas.

As dicas fornecidas durante a atividade foram numeradas para serem lidas à medida que cada equipe parar com sua ficha sobre a casa com o número referente. As dicas cunhadas foram:

1- O pé é uma das áreas corporais bastante afetadas pelo vilão deste caso, exigindo atenção e cuidados especiais.

2- Este vilão provoca dificuldades de cicatrização.

3- Atividade física controlada por profissionais especializados é uma boa forma de combater o vilão deste caso.

4- Um dos sintomas causados por este vilão é a poliúria (aumento do volume urinário).

5- Uma medida não farmacológica para controlar o vilão deste caso é a moderação ao ingerir carboidratos como massas e doces.

6- A Acarbose é uma droga capaz de combater o vilão deste caso, mas pode provocar flatulência (acúmulo de gases) por interferir na absorção intestinal de carboidratos.

7- Uma medida que auxilia a combater este vilão é ter hábitos alimentares saudáveis, como o consumo de frutas e verduras.

8- De forma a tentar controlar este vilão, o rim elimina através da urina excessos de um composto cuja fórmula molecular é $\mathrm{C} 6 \mathrm{H} 12 \mathrm{O}$.

9- O vilão deste caso provoca polifagia (fome excessiva).

10- A hiperglicemia é um sintoma marcante provocado por este vilão.

11- A Clorpropamida pode ser utilizada para combater este vilão, porém só é eficaz em paciente que ainda apresente capacidade de produção de um dos hormônios do pâncreas.

R. B. E. C. T., vol 5, núm 1, jan./abr. 2012 ISSN - 1982-873X 
12- Em decorrência do não controle do vilão deste caso pode ocorrer miocardiopatia (como, por exemplo, o infarto agudo do miocárdio).

13- Hálito cetônico pode estar presente quando o vilão deste caso não está controlado.

14- O excesso de insulina está relacionado à engorda apresentada como sintoma em determinados pacientes acometidos por este vilão.

15- Metformina é uma droga que combate o vilão deste caso, causando como efeito colateral redução de apetite. Porém, quando utilizada por paciente que não apresenta este vilão, pode induzir hipoglicemia.

16- O vilão deste caso pode levar à aterosclerose (formação de placas de gorduras depositadas nos vasos sanguíneos).

17- A polidipsia (sede em demasia) gerada por este vilão se dá em decorrência da atuação renal para combater tal vilão.

18- A falta de insulina está relacionada ao emagrecimento apresentado como sintoma em determinados pacientes acometidos pelo vilão deste caso.

19- A retinopatia pode ser uma das complicações provocadas por este vilão.

20- O vilão deste caso, quando não controlado, pode induzir cetogênese (formação de compostos cetônicos) que provoca acidez sanguínea e pode levar o paciente ao coma.

Para garantir que todas as dicas fossem lidas, dois recursos foram utilizados: (1) o dado empregado no jogo foi confeccionado com apenas números de 1 a 4 . Uma face com o número um, duas faces com número dois, duas faces com número três e uma face com número 4. E (2) mesmo que uma equipe já tivesse alcançado a casa chegada, as outras equipes deveriam dar continuidade à dinâmica do jogo para estabelecer uma ordem de chegada.

Após a explicação das regras do jogo, o pesquisador dirigiu a distribuição dos alunos em cinco grupos conforme previsto pela regra 2 e cada grupo recebeu uma ficha feita de EVA colorido para representá-lo durante o desenvolvimento do jogo.

Na sequência, o pesquisador orientou a definição da ordem de participação dos grupos no jogo, segundo a regra 4. Os grupos foram dispostos ao redor do tabuleiro de jogo. Iniciou-se, então, a partida.

À medida que os grupos andaram o número de casas indicado pelo lançamento do dado, o pesquisador leu a dica referente ao número da casa em que a ficha do grupo se encontrava.

O jogo foi desenvolvido nessa dinâmica até que uma equipe alcançou a casa CHEGADA. Nesse momento foi realizada a pergunta final: QUEM É O VILÃO DESSE CASO? 
As outras equipes deram continuidade ao jogo até que se estabeleceu uma ordem de chegada de todos os grupos. À medida que as equipes concluíram o jogo, receberam suas premiações.

A coleta de dados da pesquisa definitiva teve início na primeira aplicação do questionário aos alunos. A continuidade na obtenção dos dados se deu durante o desenvolvimento do jogo Detetive da Saúde, quando o pesquisador observou as relações entre os participantes do grupo, a dinâmica em que o jogo se efetivou e as reações dos jogadores.

$\mathrm{Na}$ aula posterior ao desenvolvimento do jogo, foi aplicado novamente o questionário, compondo uma nova fase da coleta de dados. Nesta etapa a correção das questões que compunham o questionário foi realizada, juntamente com os discentes. Também foram demonstradas as relações entre as dicas fornecidas durante o jogo e as questões. Na sequência realizou-se uma entrevista individual com os participantes da pesquisa.

\section{Resultados}

De forma a facilitar a visualização dos resultados obtidos pela aplicação do questionário foi confeccionado um gráfico que fornece lado a lado, o aproveitamento dos participantes da pesquisa (indicados por Sx) no mesmo questionário aplicado antes e depois do desenvolvimento do jogo Detetive da Saúde.

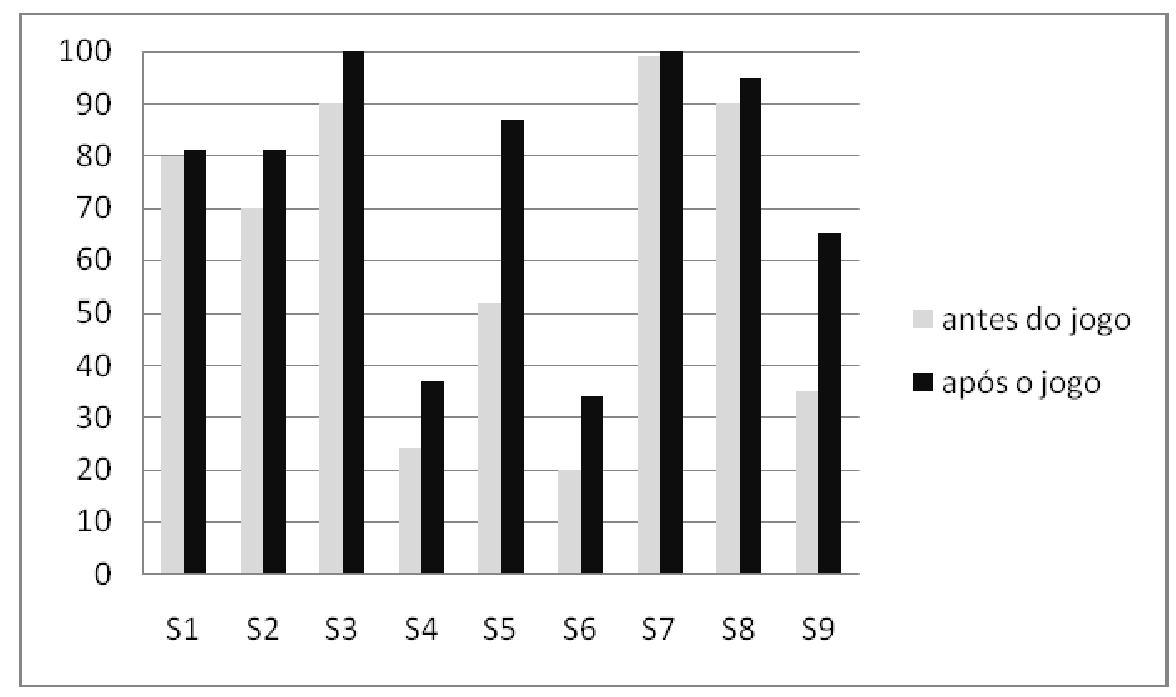

Gráfico 1: Comparação do percentual de acertos dos participantes da pesquisa, antes e depois do desenvolvimento do jogo Detetive da Saúde

Fonte: o autor

A média de global da turma antes do desenvolvimento do Detetive da Saúde foi de 62,2 e após a utilização do jogo 75,6 . Dos nove participantes da pesquisa, quatro (44,4\% da turma) apresentaram acréscimo maior que $54 \%$ em seu aproveitamento após o desenvolvimento do 
jogo. Dois participantes (22,2\% da turma) apresentaram incremento entre 11 e $54 \%$ no seu aproveitamento. E três participantes (33,3\% da turma) apresentaram elevação menor que $10 \%$ no aproveitamento. Cabe salientar que estes 3 alunos (S1, S7 e S8) apresentaram, já na primeira aplicação do questionário, notas maiores que a média da turma (80, 99 e 90, respectivamente). Tal informação torna-se relevante ao verificar que, quanto maior a nota inicial, menor é o percentual que seu incremento de aproveitamento representa. É possível, então, verificar elevação do aproveitamento de todos os participantes da pesquisa. Tal constatação quantitativa aponta o jogo Detetive da Saúde como meio de ensino capaz de contribuir positivamente com o ensino e a aprendizagem, porém a ênfase deste estudo é qualitativa e será melhor abordada com os dados coletados a partir da aplicação de entrevista.

Muitas contribuições foram trazidas pelos sujeitos da pesquisa a partir das entrevistas. Dentre as percepções evidenciadas nos relatos dos discentes, se destaca a facilidade de aprender que foi proporcionada pelo jogo Detetive da Saúde. Esta facilidade vai ao encontro do referencial teórico, no qual Dohme (2006) apoia a utilização de jogos de diversas maneiras educativas. Ainda aponta o jogo como uma forma de os professores aperfeiçoarem suas práticas pedagógicas. Essa informação pode ser visualizada na fala "com esse jogo foi melhor porque o que eu não tinha aprendido, não tinha conseguido captar durante as aulas e eu captei melhor no jogo" (S1).

Outra percepção é a maior atenção que os alunos dispensaram durante a aula com o jogo. Tal fato é asseverado por Neves e Pereira (2006) e pode ser ratificado na fala dos participantes. A competição entre os jogadores e adversários permite que o jogador ultrapasse seus limites ao almejar vencer. E nesse desejo, os alunos impelem maiores esforços. O elemento tensão, presente no jogo, é auxiliar nesse contexto.

A descontração percebida pelos discentes durante a atividade é uma das características que devem estar presentes nos jogos. O referencial teórico abaliza que o jogo é liberdade, é uma atividade voluntária, é exterior à vida cotidiana. E essas características trazem à atividade o legado da descontração, presente em recortes como "você visualiza, na prática, de uma maneira descontraída" (S2).

O maior envolvimento relatado em trechos como "a gente se envolve mais do que estar só sentado, aprendendo o conteúdo" (S4) está de acordo com o que Gramigna (2007) prevê para a fase da vivência em seu ciclo da aprendizagem vivencial (CAV). Esse envolvimento visa estimular e motivar os participantes para fases futuras do CAV.

Outra percepção relativa à atividade pesquisada está presente em trechos que apontam para a distração que ocorre com os participantes durante o jogo. Ao mesmo tempo em que a ludicidade é fator capaz de tornar a atividade significativa, a descontração proporcionada pode 
acarretar em dispersão dos alunos por conversas paralelas ou pela própria competição que o jogo proporciona. Gramigna (2007) assegura o processamento como uma das fases de seu CAV. Esse processamento visa elencar, por exemplo, dificuldades e facilidades para desenvolver a atividade. E a distração foi um tema bastante presente nas entrevistas, podendo ser considerado como uma percepção negativa quanto ao jogo. De outro modo, a etapa subsequente do CAV é a generalização, onde os participantes devem comparar o jogo com a realidade laboral. Uma articulação relevante acerca deste item vai ao encontro da teoria ausubeliana da aprendizagem significativa: a intencionalidade. Esse querer aprender, conforme emerge no referencial teórico, é fundamental para a aprendizagem e pode ser visualizado no recorte

"... vai de cada um querer levar a sério, prestar atenção no jogo, não querer dispersar, querer participar mais do jogo, ver o jogo de uma forma adulta, querer aprender vai de pessoa prá pessoa." (S1)

Verifica-se ainda, que tal jogo consolidou o referencial teórico fundamentado no Ciclo da Aprendizagem Vivencial (Gramigna, 2007), pois permitiu o desenvolvimento e a conclusão de todas as fases do CAV. O recorte da fala dos sujeitos da pesquisa que deixa claro a contribuição da atividade ao ensino, à aprendizagem e à prática profissional é

"Através de uma dica a gente consegue brincar, ficar em dúvida, a gente tem medo de responder, a gente tem medo de chegar e não saber a resposta, $e$ através das dicas a gente vai montando tudo. E agora com esse jogo da diabetes, no começo eu não sabia o que era. Quando foi falado que você pode resolver esse problema através da atividade física, você já vai assimilando as coisas. Tanto que tem muitas coisas que eu não vou esquecer por causa do jogo. Por que a gente deu risada, aí eu lembro e vou saber orientar na farmácia." (S1)

A necessidade de conhecimentos prévios para melhor aproveitar o jogo Detetive da Saúde é assinalada pelos participantes em recortes como "eu acho que o ponto negativo do jogo é que tem que ter uma teoria antes prá saber" (S8). Essa necessidade corrobora a teoria ausubeliana. Segundo esse referencial, o aluno constrói significados no momento em que estabelece interações entre o que conhece de aprendizagens anteriores e o que aprende de novo. Assim sendo, o jogo é um dos meios de ensino que compõe o método. Nesta pesquisa em específico, a aula com exposição pelo professor é o outro componente do método. E é através desse outro meio de ensino que são fornecidos os subsunçores necessários à aprendizagem significativa.

Dessa forma, o jogo possibilita ao discente reaviar (Moreira, 2008) os subsunçores formados durante a assimilação obliterativa, propiciando uma reconciliação integradora (conforme apresentado no referencial teórico). E, ao permitir a revisão de conceitos a partir das informações contidas no jogo, o Detetive da Saúde possibilita maior retenção (idem) de 
conteúdos, conforme elucidado no trecho: "se você souber alguma coisa sobre o assunto, o jogo vai ser para fixação" (S2).

Fundamentado no exposto no referencial teórico, para que a aprendizagem possa ser significativa, as interações entre conhecimentos prévios e novos devem ser não-literal e nãoarbitrária. Não-literal porque o novo conhecimento deve ser internalizado baseado em significados pessoais ou de uma comunidade. Tal interação pode ser evidenciada no recorte "o jogo ajudou a saber mais. Juntando o que eu sabia com o que eu vi no jogo daí eu vou saber informar a pessoa (S3)". E as interações ainda devem ser não-arbitrárias por que ocorrem com um conhecimento específico, conforme encontrado no trecho "o jogo tem que ser depois de você já ter explicado o conteúdo" (S9).

Outras características que apontam o Detetive da Saúde como uma atividade capaz de proporcionar uma aprendizagem significativa está na relação entre as teorias estudadas e a prática profissional. Essa vinculação é tendência atual dos cursos da área da saúde (Lampert, 2002) e pode ser evidenciada em recortes como "a aula de jogo é meio que uma prática. E na aula prática você aprende mais porque você está fazendo. E você fazendo, você aprende" (S3). A ludicidade, o dinamismo, a competição são apontadas por Isbster (2010) como características que também devem estar presentes nos jogos. Tais características são encontradas de trechos como: "aí no jogo é mais fácil, é mais dinâmico" (S5); "todo mundo presta atenção querendo ganhar" (S7).

O método de ensino proposto neste estudo envolve, além do jogo como meio de ensino, a aula com exposição pelo professor. Neste outro meio de ensino, a ação receptiva que cabe ao aluno é encontrada em fragmentos como "e você só ouvindo e vendo você pode não prestar atenção. Pode estar só anotando e não aprendendo, só copiando" (S3). Porém, a exposição pelo professor se apresenta relevante no método em questão. O recorte "a aula normal é uma aula mais centrada. Tem certas coisas que você não pode dispersar prá você entender" (S9) demonstra que, quando o professor consegue mobilizar a atenção do aluno, tal meio é um importante procedimento para se obter conhecimento (Libâneo, 1994). A maior seriedade com que a aula expositiva é conduzida, quando comparada com a aula com jogos, e a possibilidade de esclarecimento de dúvidas que o jogo não proporcionou também emergiram em trechos como "o ponto positivo é que é uma coisa séria mesmo, a gente pode tirar dúvidas" (S1). 


\section{Considerações Finais}

As percepções apontadas pelos participantes do estudo apontaram o emprego do método amparado em dois meios de ensino (aula com exposição pelo professor e o jogo anteriormente citado) como capaz de contribuir positivamente com o processo de ensino e aprendizagem.

Os participantes relatam a validade de utilizar a aula com exposição pelo professor como um meio de ensino, devido permitir maior atenção e seriedade durante a atividade, bem como oferecer conhecimentos necessários (subsunçores) a um melhor aproveitamento do jogo (o outro meio de ensino proposto pelo método). O jogo Detetive da Saúde, por sua vez, cumpriu seu propósito como meio de ensino. Através da ludicidade conferiu à atividade o dinamismo tornando-a potencialmente significativa.

Para a aula com exposição pelo professor, os discentes apontam para a falta de dinamismo e a facilidade de distração como pontos negativos. No entanto, também apontaram a facilidade de distração como um ponto negativo para a aula com jogos. Nesse momento, emergiu dos próprios sujeitos da pesquisa a possível solução para esta característica: a intencionalidade. De nada adianta utilizar meios e métodos de ensino se o aluno não desejar que tal atividade cumpra o legado da aprendizagem. Essa informação é prevista na Teoria da Aprendizagem Significativa (Ausubel, 1980) e fundamentada no referencial teórico deste estudo.

Cabe aqui salientar a individualidade dos sujeitos. Há indivíduos que se adaptam melhor às aulas expositivas, bem como há indivíduos com preferência pela aula com jogos, assim como há a preferência pela aprendizagem simples e pura. E imbuído da clareza sobre essa diversidade, cabe ao professor selecionar os métodos e meios mais adequados à obtenção do desígnio proposto para aquela atividade, assunto ou conteúdo. Assim, a utilização de diferentes meios e métodos, por parte do docente, visa dar a cada sujeito, a partir da sua intencionalidade, a possibilidade da construção do conhecimento seja para seu crescimento, seja para o aperfeiçoamento de sua prática profissional.

Outra verificação sobreveio aos dados coletados na primeira pergunta feita durante a entrevista utilizada na pesquisa: você já participou de jogos em sala de aula? Quais? Que tipo? Quais disciplinas? Para estas perguntas, todos os sujeitos relataram que não haviam desenvolvido atividades similares ou de mesmo cunho durante o curso profissionalizante. Assim sendo, o presente artigo objetiva dar visibilidade a este estudo e torná-lo uma contribuição ao ensino.

Por fim, se recomenda apenas a utilização esporádica do Detetive da Saúde. A necessidade de uma hora-aula para o desenvolvimento da atividade lúdica ao término de cada tema pode comprometer o cumprimento do ementário da disciplina dentro da carga-horária prevista para tal. Além de a utilização freqüente de atividades em grupo minimizar o fator tensão, exposto anteriormente como relevante à atividade. Sugere-se, então, que a aplicação do jogo não se dê 
imediatamente após cada tema trabalhado, mas como uma atividade própria para o encerramento de um ciclo como um semestre ou módulo, por exemplo.

\section{Referências}

Assis, Monica de. Uma nova sensibilidade nas práticas de saúde. Interface (Botucatu). v.5, n.8, p. 139-140, 2001. Disponível em: <http://www.scielo.br/pdf/icse/v5n8/14.pdf>. Acesso 04 set. 2010. AusubeL, David Paul; Novak, Joseph Donald; Hanesian, Helen. Psicologia educacional. 2. ed. Rio de Janeiro: Interamericana, 1980.

Berbel, Neusi Aparecida Navas. A problematização e a aprendizagem baseada em problemas: diferentes termos ou diferentes caminhos? Interface (Botucatu). v.2, n.2, p. 139-154, 1998. Disponível em: <http://www.scielo.br/pdf/icse/v2n2/08.pdf>. Acesso 08 set. 2010.

Bordenave, Juan Díaz; Pereira Adair Martins. Estratégias de ensino-aprendizagem. 15. ed. Petrópolis: Vozes, 1995.

Colégio Sant`Ana. Documento de renovação do curso técnico em farmácia. Ponta Grossa, 2004. Cyrino, Eliana Goldfarb; TORALLES-PEREIRA, Maria Lúcia. Trabalhando com estratégias de ensinoaprendizado por descoberta na área da saúde: a problematização e a aprendizagem baseada em problemas. Cadernos de Saúde Pública. v.20, n.3, p. 780-788, 2004. Disponível em:

<http://www.scielo.br/pdf/csp/v20n3/15.pdf >. Acesso 19 set. 2010.

Dohme, Vania. Atividades lúdicas na educação: o caminho de tijolos amarelos. Vania Dohme, Petrópolis, Rio de Janeiro: Vozes, 2003.

Flexner Abraham. Medical Education in the United States and Canada. New York: Carnegie Foundation for The Advancement of Teaching; 1910. (Bulletin, 4)

Gramigna, Maria Rita Miranda. Jogos de empresas e técnicas vivenciais. Pearson Prentice Hall. 2. ed. 2007.

Goodman \& Gilmam. As bases farmacológicas da terapêutica. Rio de Janeiro : McGraw-Hill Interamericana do Brasil, 2006.

Huizinga, Johan. Homo Ludens. Trad. João Paulo Monteiro. São Paulo: Editora Perspectiva, 2000. Isbister, Katherine; Flanagan, Mary; Hash, Chelsea. Designing games for learning: insights from conversations with designers. Remember and Reflect. Atlanta, 2010. Disponível em:

$<$ http://www.livelydisposition.com/wpcontent/uploads/2010/07/isbister_flanagan_hash_CHI.pdf >. Acesso 28 set. 2010. 
Kishimoto, Tizuko Morchida (Org). Jogo, brinquedo, brincadeira e a educação. 10. ed. São Paulo: Cortez, 2007.

Kishimoto, Tizuko Morchida. O brincar e suas teorias. São Paulo: Pioneira, 1998.

Lakatos, Eva Maria; Marconi, Marina de Andrade. Fundamentos de metodologia científica. 6. ed. São Paulo: Atlas, 2009.

Lampert, Jadete Barbosa. Tendências de mudanças na formação médica no Brasil. 2002. 209f.

Tese (Doutorado em Saúde Pública) - Fundação Osvaldo Cruz “Maria Cecília de Souza Minayo" Rio de Janeiro, 2002.

Libâneo, José Carlos. Didática. 2. ed. São Paulo: Cortez; 1994.

Macedo, Laura Christina; Larocca, Liliana Muller; Chaves, Maria Marta Nolasco; MAZZA, Verônica de Azevedo. Análise do discurso: uma reflexão para pesquisar em saúde. Interface (Botucatu). v.12, n.26, p. 649-657, 2008. Disponível em: <http://www.scielo.br/pdf/icse/v12n26/a15.pdf>. Acesso 13 set. 2010.

Moreira, Herivelto; Caleffe, Luiz Gonzaga. Metodologia da pesquisa para o professor pesquisador. 2. ed. Rio de Janeiro : Lamparina, 2008.

Moreira, Marco Antônio; Masini, Elcie F. Salzano. Aprendizagem significativa: condições para ocorrência e lacunas que levam a comprometimentos. São Paulo: Vetor, 2008.

Murcia, Juan Antônio Moreno. Aprendizagem através de jogos. Porto Alegre: Artmed, 2005. Neves, Marcos Cesar Danhoni; Pereira, Ricardo Francisco. Divulgando a ciência: de brinquedos, jogos e do voo humano. 1. ed. - Maringá : Massoni, 2006.

Okane, Eliana Suemi Handa; Takahashi, Regina Toshie. O estudo dirigido como estratégia de ensino na educação profissional em enfermagem. Revista escola de enfermagem. USP, v.40, n.2, p. 160-169, 2006. Disponível em: <http://www.scielo.br/pdf/reeusp/v40n2/02.pdf>. Acesso 13 set. 2010.

Pagliosa, Fernando Luiz; Da Ros, Marco Aurélio. O relatório Flexner: para o bem e para o mal.

Revista brasileira educação médica. v.32, n.4, p. 492-499, 2008. Disponível em:

<http://www.scielo.br/pdf/rbem/v32n4/v32n4a12.pdf>. Acesso 08 set. 2010.

Pimentel, Alessandra. Jogo e desenvolvimento profissional: análise de uma proposta de formação continuada de professores. 225f. Tese (Doutorado em Educação) - Universidade de São Paulo, 2004.

Sant'anna, Flávia Maria; Enricone, Délcia; André, Lenir Cancella; Turra, Clódia Maria Godoy. Planejamento de ensino e avaliação. 11. ed. Porto Alegre: Sagra / DC Luzzatto, 1995.

Silva, Penildon. Farmacologia. 7. ed. Rio de Janeiro: Guanabara Koogan, 2006. 
José Fabiano Costa Justus. Universidade Estadual de Ponta Grossa. Atualmente é professor da Universidade Estadual de Ponta Grossa e Itecne Pós Graduação. Mestre em Ensino de Ciência e Tecnologia pela Universidade Tecnológica Federal do Paraná. jfcjustus@uepg.br

Antonio Carlos de Francisco. Universidade Tecnológica Federal do Paraná. Professor dos Programas de Pós-Graduação em Engenharia de Produção e de Ensino de Ciência e Tecnologia da UTFPR, Campus Ponta Grossa. Doutor em Engenharia de Produção pela Universidade Federal de Santa Catarina. acfrancisco@utfpr.edu.br 